\title{
Expression of beclin 1 in primary salivary adenoid cystic carcinoma and its relation to $\mathrm{Bcl}-2$ and $\mathrm{p} 53$ and prognosis
}

\author{
L.C. Jiang*, S.Y. Huang*, D.S. Zhang, S.H. Zhang, W.G. Li, P.H. Zheng and Z.W. Chen
}

Department of Oral and Maxillofacial Surgery, Shandong Provincial Hospital Affiliated to Shandong University, Jinan, China

\begin{abstract}
Beclin 1 plays a critical role in autophagy and functions as a haploinsufficient tumor suppressor. The expression and prognostic significance of beclin 1 in head and neck adenoid cystic carcinoma (ACC) are largely unexplored. Therefore, we investigated the expression of beclin 1, Bcl-2, and p53 in head and neck ACC tissue. Tissue samples from 35 cases (15 females, 20 males) of head and neck ACC were utilized for immunohistochemistry. Beclin 1 expression was observed in 32 cases (91.4\%) and considered to be high in 15 cases (42.9\%) and low in 20 cases (57.1\%). Beclin 1 expression was significantly correlated with a histological growth pattern $(P=0.046)$ and histological grade $(P=0.037)$. Beclin 1 expression was inversely correlated with $\mathrm{Bcl}-2$ expression $(P=0.013)$ and significantly associated with overall survival $(P=0.006)$. Bcl-2 and p53 expression were observed in 21 cases $(60.0 \%)$ and 16 cases (45.7\%). Bcl-2 expression was significantly correlated with perineural invasion $(P=0.041)$ and not associated with overall survival $(P=0.053)$. p53 expression was directly correlated with beclin 1 expression $(P=0.044)$. Our results indicated that beclin 1 may be a novel, promising prognostic factor for clinical outcome in head and neck ACC patients and may play a part in the development of head and neck ACC by interacting with Bcl-2 and p53.
\end{abstract}

Key words: Adenoid cystic carcinoma; Autophagy; Beclin 1; Bcl-2; p53

\section{Introduction}

Adenoid cystic carcinoma is one of the most frequent malignant salivary gland tumors in the head and neck region. The clinical and pathological characteristics include slow growth, perineural invasion, distant metastasis, and potential local recurrence $(1,2)$. Although complete surgical resection and additional radiotherapy have been shown to improve long-term survival, the prognosis of adenoid cystic carcinoma remains poor $(3,4)$. Accordingly, it is very important to objectively predict the assessment of prognosis for resected patients and the development of metastasis.

Autophagy is an evolutionarily conserved catabolic process where cellular cytoplasmic contents are selfdigested (literally "eats itself") (5). In eukaryotic cells, autophagy is a primary mechanism for long-lived protein degradation and organelle turnover, serving as a critical adaptive response that recycles energy and nutrients during starvation or stress (6). Autophagy is regulated by a set of highly conserved genes called ATGs (for
AuTophaGy gene) (7). Beclin 1 gene is identified as the mammalian ortholog of yeast Atg6 and plays a pivotal role in mammalian autophagy.

The human beclin 1 gene is located on chromosome $17 q 21$ (8). The role of autophagy as a tumor suppressor was first broached through genetic studies of beclin 1, and beclin 1 was mapped to a tumor susceptibility locus monoallelically deleted and with a high proportion of human breast, intrahepatic biliary duct, ovarian, and brain cancers. In addition, analysis of human tissue samples revealed that there was a significant loss of beclin 1 protein expression in human breast carcinomas compared to normal breast tissue (9-13). Ectopic beclin 1 expression decreased cancer cell proliferation in vitro and reduced tumorigenic potential in vivo, further illustrating a role for autophagy in tumor suppression. In support of this concept, two groups illustrated that heterozygous disruption of beclin 1 promoted tumorigenesis in mice, albeit over an extended latency $(14,15)$. These findings demonstrate that

Correspondence: D.S. Zhang, Department of Oral and Maxillofacial Surgery, Shandong Provincial Hospital Affiliated to Shandong University, 324 Jingwu Road, Jinan 250021, China. Fax: +86-531-8703-5697. E-mail: ds63zhang@sdu.edu.cn

*These authors contributed equally to this study.

Received June 11, 2013. Accepted September 25, 2013. First published online January 29, 2014. 
beclin 1/atg6 functions as a haploinsufficient tumor suppressor.

$\mathrm{Bcl}-2$, the first protein found to interact with beclin 1, was shown to possess an anti-autophagy function in addition to its well-established role in apoptosis inhibition (16). Because these anti-apoptotic proteins are usually overexpressed in cancer cells, the $\mathrm{Bcl}-2$ protein may have an additive effect on oncogenic properties through inhibition of autophagy (17).

p53, as a tumor suppressor gene, downregulates $\mathrm{Bcl}-2$ transcription activity and plays a duplicate role in autophagy regulation, depending on its subcellular location, and the mutation of $p 53$ is one of the most common genetic events described in human cancers. Immunohistochemical staining for p53 usually shows mutant types of p53 facilitating malignant transformation $(18,19)$. Furthermore, immunohistochemistry of p53 proteins in tumor cells may serve as an additional method to evaluate the status of other important tumor genes (20). Expression of beclin 1 and Bcl-2, an association with p53 expression, as well as any correlation between beclin 1 expression and clinicopathological factors or outcomes in adenoid cystic carcinoma, have not been well characterized.

We investigated the expression of beclin 1, Bcl-2, and p53 in head and neck adenoid cystic carcinoma tissue via immunohistochemical analysis in relation to survival and other prognostic factors.

\section{Material and Methods}

\section{Patients and specimens}

All of the tissues analyzed were obtained from 35 consecutive patients (15 females, 20 males) with head and neck adenoid cystic carcinoma who underwent a primary resection between December 2002 and March 2010 at Shandong Provincial Hospital, affiliated with Shandong University of China. All patients gave written informed consent to participate in the study. Two independent observers reviewed all of the original hematoxylin and eosin-stained sections and chose the most representative slide from each case to perform immunohistochemical staining. Two or three representative cores, $3 \mathrm{~mm}$ in diameter, were obtained from a representative area of each paraffin-embedded tumor tissue. The median age of the patients was 47.8 years (range, 18-72 years), and tumor size ranged from 0.7 to $4 \mathrm{~cm}$ (median size, $1.8 \mathrm{~cm}$ ). According to the American Joint Committee on Cancer staging criteria (tumor-nodemetastasis: TNM), 12 patients (34.3\%) had Stage I and II disease, and 23 patients $(65.7 \%)$ had Stage III and IV disease. Three histological grades were established: Grade I, tumors with tubular and cribriform areas but without solid components; Grade II, cribriform tumors that were either pure or mixed with less than $30 \%$ of solid areas; and Grade III, tumors with a predominantly solid pattern (21).

\section{Immunohistochemical staining}

Sections ( $4 \mu \mathrm{m}$ thick) of formalin-fixed, paraffinembedded tissue were deparaffinized, dehydrated via a graded alcohol series, and subjected to blocking with hydrogen peroxide. An antigen retrieval procedure was performed by microwave in $10 \mathrm{mM}$ citrate buffer, $\mathrm{pH} 6.0$. Sections were incubated for $15 \mathrm{~min}$ at room temperature with primary monoclonal antibodies for beclin 1 (1:50, Abcam, UK) and Bcl-2 (1:200, Abcam), and monoclonal antibodies for p53 (1:300 Abcam) using a biotin-free polymeric horseradish peroxidase linker antibody conjugate system, and nuclei were counterstained with hematoxylin in a BenchMark ULTRA advanced staining system (Ventana Medical Systems, USA). The positive controls were supplied by Abcam, and negative controls were obtained by omitting primary antibody replaced by PBS.

\section{Evaluation of immunohistochemical staining}

The expression of beclin 1 ascertained by immunohistochemical staining emerged as fine granular and diffuse staining in the plasma membrane, cytoplasm, and/or nucleus of tumor cells. Bcl-2 expression was discerned in the cytoplasm and p53 was seen in the cell nucleus of adenoid cystic carcinoma. Immunohistochemical staining for beclin 1 was evaluated in compliance with intensity and proportion. The intensities were scored as 0 (no staining), 1 (weak staining), 2 (moderate staining), and 3 (strong staining). The percentage of staining area was classified as 0 ( $<5 \%$ of tumor cells), 1 (6-25\% of tumor cells), 2 (26$50 \%$ of tumor cells), 3 (51-70\% of tumor cells), and 4 ( $>70 \%$ of tumor cells) (22). Scores for intensity and proportion were multiplied to give a total score. The staining pattern of the slides was defined as follows: 0 to 3 (low beclin 1 expression) and 4 to 7 (high beclin 1 expression) (23). Tumor cells were considered immunopositive for Bcl-2 and p53 when stained in $30 \%$ or more of the cells $(22,24)$. All slides were evaluated independently by two observers without clinicopathological information.

\section{Statistical methods}

Statistical analysis was performed using the SPSS software package (version 16.0; SPSS, USA). A P value of less than 0.05 was considered to be significant. Association was evaluated according to the Fisher exact test between beclin 1, Bcl-2, and p53 expression and several clinicopathological variables. The Kaplan-Meier method was applied to determine the probability of survival, and data were analyzed by applying the log-rank test. Overall survival was defined as date of surgery to date of death due to cancer.

\section{Results}

\section{Beclin 1 expression and its association with clinicopathological variables}

Normal head and neck glands showed moderate to strong beclin 1 expression (Figure 1). Beclin 1 expression 

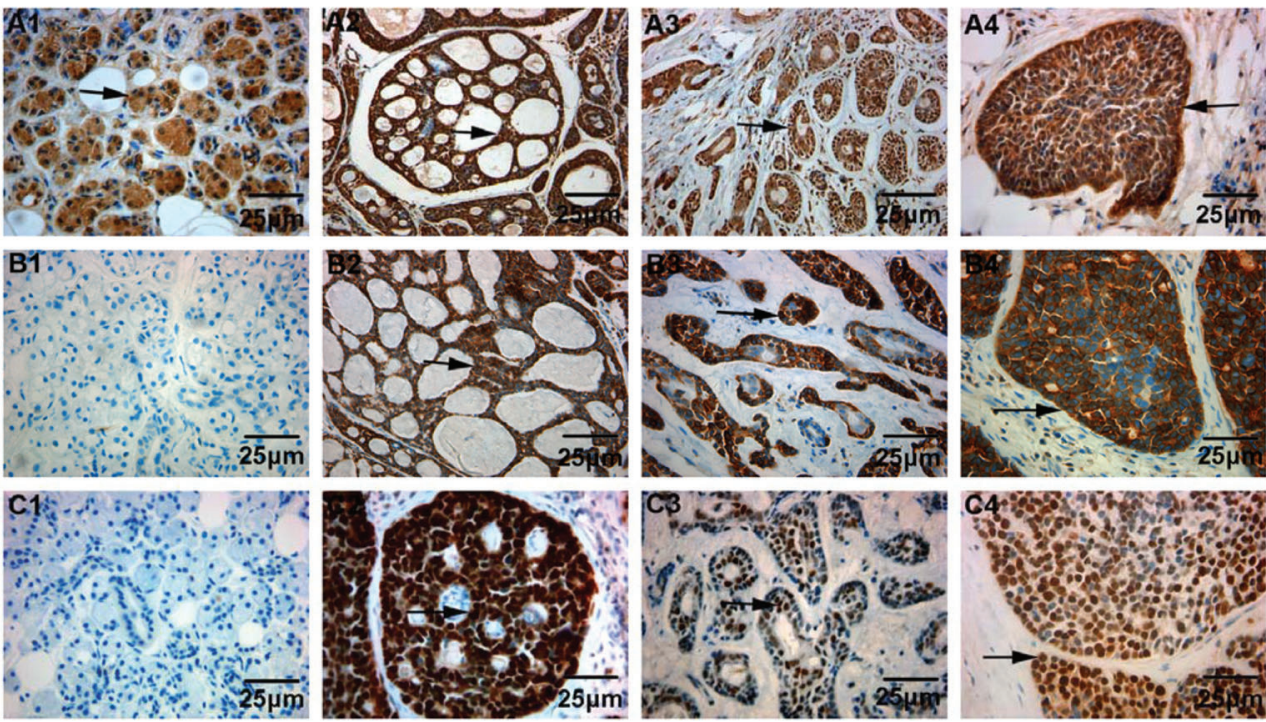

Figure 1. Positive beclin 1 expressed in normal salivary gland (A1) and in cribriform (A2), tubular (A3), and solid (A4) pattern of adenoid cystic carcinomas (ACCs). Negative Bcl-2 expressed in normal salivary gland (B1) and positive Bcl-2 in cribriform (B2), tubular (B3), and solid (B4) pattern of ACCs. Negative p53 expressed in normal salivary gland (C1) and positive p53 in cribriform (C2), tubular (C3), and solid (C4) pattern of ACCs.

was also found in the plasma membrane, cytoplasm, and/ or nucleus of tumor cells. Beclin 1 expression was present in 32 cases (91.4\%; see Figure 2) and considered to be high in 15 cases $(42.9 \%)$ and low in 20 cases $(57.1 \%)$. The correlations between beclin 1 and clinical variables are listed in Table 1. Beclin 1 expression was significantly correlated with histological growth patterns $(P=0.046)$

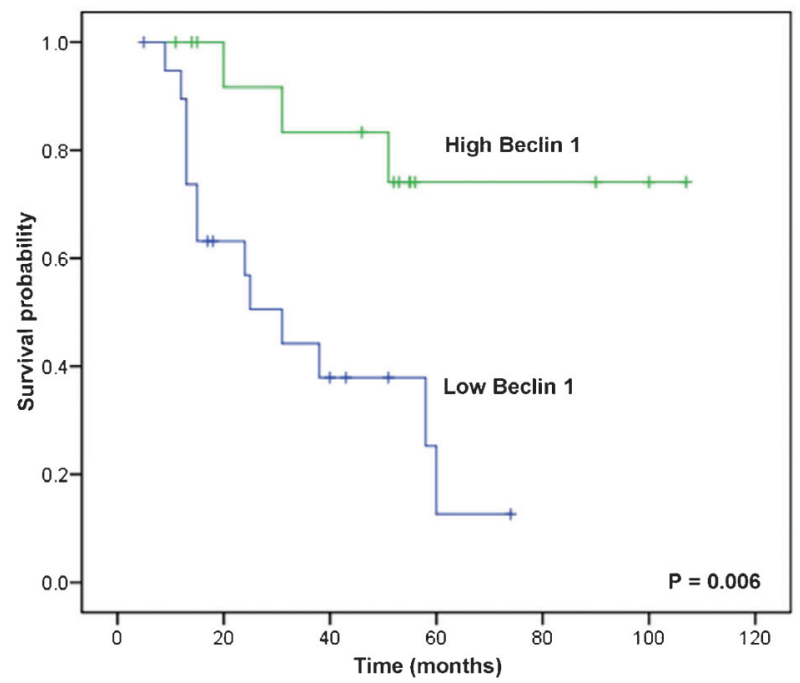

Figure 2. Cumulative Kaplan-Meier survival curve (beclin 1) showing that survival in the high beclin 1 expression group $(n=15)$ tended to be better than in the low beclin 1 expression group $(n=20)$. and histological grade $(P=0.037)$. Beclin 1 expression was not significantly associated with age $(P=0.741)$, gender $(P=1.000)$, primary site $(P=1.000)$, TNM stage $(P=1.000)$, lymph node involvement $(P=0.365)$, tumor size $(P=0.430)$, perineural invasion $(P=0.738)$, perivascular invasion $(P=1.000)$, or lymphatic invasion $(P=1.000)$.

\section{$\mathrm{Bcl}-2$ expression and its association with clinicopathological variables}

Positive $\mathrm{Bcl}-2$ expression of adenoid cystic carcinoma was observed in 21 cases (60.0\%; see Figure 1). Correlations between $\mathrm{Bcl}-2$ and clinical variables are listed in Table 1. Bcl-2 expression in head and neck adenoid cystic carcinoma was significantly correlated with perineural invasion ( $P=0.041$; Table 1). Bcl-2 expression was not significantly associated with age $(P=1.000)$, gender $(P=1.000)$, primary site $(P=0.282)$, TNM stage $(P=1.000)$, lymph node involvement $(P=1.000)$, tumor size $(P=1.000)$, histological growth pattern $(P=0.089)$, histological grade $(P=0.296)$, perivascular invasion $(P=0.635)$, or lymphatic invasion $(P=0.369)$.

\section{p53 expression}

As shown in Table 1, positive p53 expression of adenoid cystic carcinoma was observed in 16 cases (45.7\%; Figure 1). In the 20 tumor tissues with low beclin 1 expression, 6 were positive and 14 were negative for p53 expression. In contrast, in the 15 tumor tissues with high beclin 1 expression, 10 were positive and 5 were negative for p53 expression. p53 expression was directly 
Table 1. Correlation between beclin 1 expression and Bcl-2 expression and clinicopathologic variables in 35 cases of head and neck adenoid cystic carcinoma.

\begin{tabular}{|c|c|c|c|c|c|c|}
\hline \multirow[t]{2}{*}{ Variables } & \multicolumn{2}{|c|}{ Beclin-1 expression } & \multirow[t]{2}{*}{$\mathrm{P}$} & \multicolumn{2}{|c|}{ Bcl-2 expression } & \multirow[t]{2}{*}{$\mathrm{P}$} \\
\hline & Low expression & High expression & & Negative & Positive & \\
\hline \multicolumn{7}{|l|}{ Age (years) } \\
\hline$<48$ & $8(22.9 \%)$ & $7(20.0 \%)$ & 0.741 & $6(17.1 \%)$ & $9(25.7 \%)$ & 1.000 \\
\hline$\geqslant 48$ & $12(34.3 \%)$ & $8(22.9 \%)$ & & $8(22.9 \%)$ & $12(34.3 \%)$ & \\
\hline \multicolumn{7}{|l|}{ Gender } \\
\hline Female & $9(25.7 \%)$ & $6(17.1 \%)$ & 1.000 & $6(17.1 \%)$ & $9(25.7 \%)$ & 1.000 \\
\hline Male & $11(31.4 \%)$ & $9(25.7 \%)$ & & $8(22.9 \%)$ & $12(34.3 \%)$ & \\
\hline \multicolumn{7}{|l|}{ Primary site } \\
\hline Major salivary gland ${ }^{a}$ & $13(37.1 \%)$ & $10(28.6 \%)$ & 1.000 & $11(31.4 \%)$ & $12(34.3 \%)$ & 0.282 \\
\hline Minor salivary gland ${ }^{\mathrm{b}}$ & $7(20.0 \%)$ & $5(14.3 \%)$ & & $3(8.6 \%)$ & $9(25.7 \%)$ & \\
\hline \multicolumn{7}{|l|}{ TNM stage } \\
\hline I, II & $7(20.0 \%)$ & $5(14.3 \%)$ & 1.000 & $5(14.3 \%)$ & $7(20.0 \%)$ & 1.000 \\
\hline III, IV & $13(37.1 \%)$ & $10(28.6 \%)$ & & $9(25.7 \%)$ & $14(40.0 \%)$ & \\
\hline \multicolumn{7}{|l|}{ Lymph node involvement } \\
\hline Absent & $16(45.7 \%)$ & $14(40.0 \%)$ & 0.365 & $12(34.3 \%)$ & $18(51.4 \%)$ & 1.000 \\
\hline Present & $4(11.4 \%)$ & $1(2.9 \%)$ & & $2(5.7 \%)$ & $3(8.6 \%)$ & \\
\hline \multicolumn{7}{|l|}{ Tumor size $(\mathrm{cm})$} \\
\hline$\leq 3 \mathrm{~cm}$ & $17(48.6 \%)$ & $11(31.4 \%)$ & 0.430 & $11(31.4 \%)$ & $17(48.6 \%)$ & 1.000 \\
\hline$>3 \mathrm{~cm}$ & $3(8.6 \%)$ & $4(11.4 \%)$ & & $3(8.6 \%)$ & $4(11.4 \%)$ & \\
\hline \multicolumn{7}{|l|}{ Histological growth pattern } \\
\hline Tubular, cribriform & $9(25.7 \%)$ & $12(34.3 \%)$ & $0.046^{*}$ & $11(31.4 \%)$ & $10(28.6 \%)$ & 0.089 \\
\hline Solid & $11(31.4 \%)$ & $3(8.6 \%)$ & & $3(8.6 \%)$ & $11(31.4 \%)$ & \\
\hline \multicolumn{7}{|l|}{ Histological grade } \\
\hline Well, moderately & $8(22.9 \%)$ & $12(34.3 \%)$ & $0.037^{\star}$ & $10(28.6 \%)$ & $10(28.6 \%)$ & 0.296 \\
\hline Poorly & $12(34.3 \%)$ & $3(8.6 \%)$ & & $4(11.4 \%)$ & $11(31.4 \%)$ & \\
\hline \multicolumn{7}{|l|}{ Perineural invasion } \\
\hline Absent & $9(25.7 \%)$ & $8(22.9 \%)$ & 0.738 & $10(28.6 \%)$ & $7(20.0 \%)$ & $0.041^{*}$ \\
\hline Present & $11(31.4 \%)$ & $7(20.0 \%)$ & & $4(11.4 \%)$ & $14(40.0 \%)$ & \\
\hline \multicolumn{7}{|l|}{ Perivascular invasion } \\
\hline Absent & $18(51.4 \%)$ & $13(37.1 \%)$ & 1.000 & $13(37.1 \%)$ & $18(51.4 \%)$ & 0.635 \\
\hline Present & $2(5.7 \%)$ & $2(5.7 \%)$ & & $1(2.9 \%)$ & $3(8.6 \%)$ & \\
\hline \multicolumn{7}{|l|}{ Lymphatic invasion } \\
\hline Absent & $17(48.6 \%)$ & $13(37.1 \%)$ & 1.000 & $11(31.4 \%)$ & $19(54.3 \%)$ & 0.369 \\
\hline Present & $3(8.6 \%)$ & $2(5.7 \%)$ & & $3(8.6 \%)$ & $2(5.7 \%)$ & \\
\hline \multicolumn{7}{|l|}{ p53 expression } \\
\hline Positive & $6(17.1 \%)$ & $10(28.6 \%)$ & $0.044^{*}$ & $6(17.1 \%)$ & $10(28.6 \%)$ & 1.000 \\
\hline Negative & $14(40.0 \%)$ & $5(14.3 \%)$ & & $8(22.9 \%)$ & $11(31.4 \%)$ & \\
\hline
\end{tabular}

${ }^{a}$ Submandibular gland, parotid gland, sublingual gland; ${ }^{b}$ maxillary sinus, nasal cavity, base of tongue, floor of the mouth, external acoustic canal. * $\mathrm{P}<0.05$, high compared to low beclin 1 expression and positive compared to negative $\mathrm{Bcl}-2$ expression ( $\chi^{2}$ test).

correlated with beclin 1 expression $(P=0.044)$, but not significantly with $\mathrm{Bcl}-2(\mathrm{P}=1.000)$.

Relationship between beclin 1 and $\mathrm{Bcl}-2$ expression As shown in Table 2, in the 20 tumor tissues with low beclin 1 expression, 4 were negative and 16 were positive for Bcl-2 expression. By contrast, in the 15 tumor tissues with high beclin 1 expression, 10 were negative and 5 were positive for $\mathrm{Bcl}-2$ expression. Beclin 1 expression was inversely correlated with $\mathrm{Bcl}-2$ expression in head and neck adenoid cystic carcinoma $(P=0.013)$.

\section{Results of the overall survival analysis}

The mean follow-up period was 38 months (range, 5107 months), and, for 35 patients, 15 died of disease, 18 were alive on the day of the study, and 2 were lost during the follow-up period. Based on the use of the KaplanMeier method, overall survival in the high beclin 1 expression group tended to be better than in the low beclin 1 expression group $(P=0.006$; see Figure 2$)$. Bcl-2 expression showed no significant difference for the overall survival rate in patients with adenoid cystic carcinoma $(P=0.053$; see Figure 3). As shown in Table 3, the absent 
Table 2. Correlation between beclin 1 expression and $\mathrm{Bcl}-2$ expression in 35 cases of head and neck adenoid cystic carcinoma.

\begin{tabular}{cccc}
\hline & \multicolumn{2}{c}{ Beclin 1 expression } & P \\
\cline { 2 - 3 } & Low expression & High expression & \\
\hline Bcl-2 & & & \multirow{2}{*}{$0.013^{*}$} \\
Negative & $4(11.4 \%)$ & $10(28.6 \%)$ & \\
Positive & $16(45.7 \%)$ & $5(14.3 \%)$ & \\
\hline
\end{tabular}

* Significantly different by the $\chi^{2}$ test.

lymph node involvement group survived better than the group with lymph nodes present $(P=0.017)$, the group with a solid histological growth pattern had worse overall survival than the group with tubular and cribriform histological growth patterns $(P=0.000)$, and the well and moderate histological grade group had better overall survival than the poor histological grade group $(P=0.000)$. Overall survival was not significantly associated with age $(P=0.185)$, gender $(P=0.793)$, primary site $(P=0.524)$, TNM stage $(P=0.606)$, tumor size $(P=0.457)$, perineural invasion $(P=0.081)$, perivascular invasion $(P=0.665)$, lymphatic invasion $(P=0.569)$, or p53 expression $(P=0.135)$.

\section{Discussion}

In this study, we demonstrated that $91.4 \%$ of patients expressed the beclin 1 protein in head and neck adenoid cystic carcinoma tissues. This phenomenon also

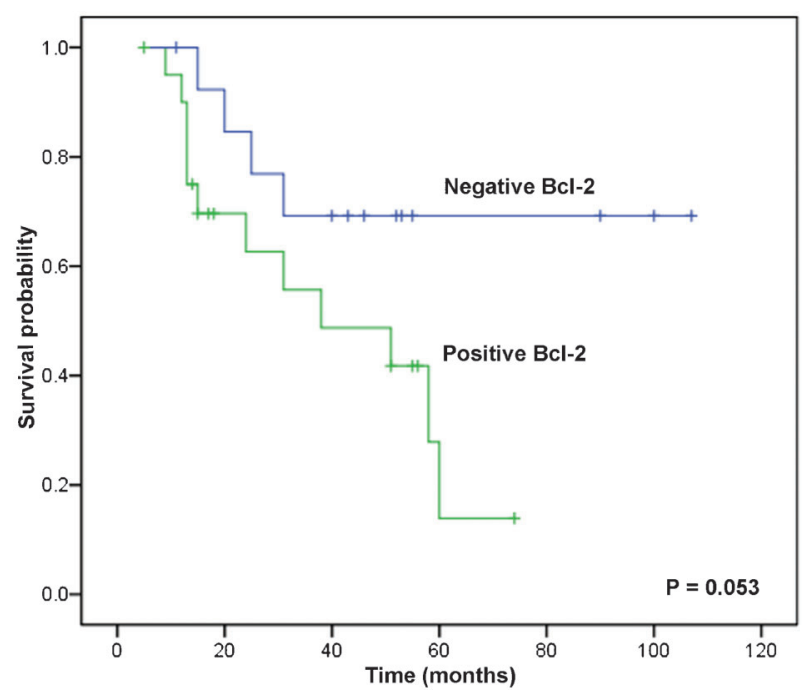

Figure 3. Cumulative Kaplan-Meier survival curve (Bcl-2) showing that the survival in the negative $\mathrm{Bcl}-2$ expression group $(n=14)$ and the positive Bcl-2 group $(n=21)$ was not significantly different.
Table 3. Analysis of 12 clinicopathologic variables for overall survival rate in 35 cases of head and neck adenoid cystic carcinoma.

\begin{tabular}{lc}
\hline Variables & $\begin{array}{c}\text { Overall survival } \\
\text { rate }(\mathrm{P})\end{array}$ \\
\hline Age $(<48 / \geqslant 48$ years) & 0.185 \\
Gender (female/male) & 0.793 \\
Primary site (major/minor) & 0.524 \\
TNM stage (I, II/III, IV) & 0.606 \\
Lymph node involvement (absent/present) & $0.017^{*}$ \\
Tumor size ( $\leq 3 \mathrm{~cm} />3 \mathrm{~cm})$ & 0.457 \\
Histological growth pattern (tubular, & $0.000^{*}$ \\
$\quad$ cribriform/solid) & \\
Histological grade (well, moderately/poorly) & $0.000^{*}$ \\
Perineural invasion (absent/present) & 0.081 \\
Perivascular invasion (absent/present) & 0.665 \\
Lymphatic invasion (absent/present) & 0.569 \\
p53 expression (positive/negative) & 0.135 \\
\hline
\end{tabular}

TNM: tumor-node-metastasis. * Significantly different by the Kaplan-Meier test.

appeared in human gastric and colorectal cancers in which the expression of beclin 1 was 83 and $95 \%$, respectively, but was different from human breast cancer, intrahepatic cholangiocellular carcinoma, chondrosarcoma, melanomas, and glioblastoma multiform tissue in which there was a significant loss of beclin 1 protein expression (10,13,24-27). In our data, beclin 1 expression was used to divide patients into two groups: one with high beclin 1 expression and one with low beclin 1 expression. Beclin 1 expression showed a statistically significant correlation with histological growth pattern and histological grade, and clinical characteristics were good in patients with high beclin 1 expression and poor in patients with low beclin 1 expression. The cumulative KaplanMeier survival curve showed that survival in the high beclin 1 expression group tended to be better than in the low beclin 1 expression group, demonstrating that beclin 1 could be a good indicator of prognosis in head and neck adenoid cystic carcinoma. Autophagy is activated in cancer cells accommodating to multiple stresses and has been demonstrated to facilitate tumor cell survival (6). However, genetic evidence supports that autophagy functions as a tumor suppressor mechanism (28). Therefore, the rigorous role of autophagy during cancer progression and treatment is both tissue and context dependent. Several potential mechanisms have emerged to explain why autophagy induced by beclin-1 may preclude cancer. First, some studies showed that autophagydefective cells demonstrate a notable increase in DNA double-strand breaks and gene amplification in response to metabolic stress compared to their autophagy-competent counterparts (29). The second potential mechanism is based on the observation that, when apoptosis is 
hampered, autophagy-incompetent cells are more prone to undergo necrosis in response to metabolic stress, whereas autophagy-competent cells are more resistant to cell death (30). In addition, a recent study demonstrated that autophagy is necessary for the establishment of oncogene-induced senescence, which provides an alternative mechanism for autophagy-mediated tumor suppression (31). Therefore, further research is required to show whether and how autophagy inhibits or promotes head and neck adenoid cystic carcinoma.

Our findings demonstrated that beclin 1 expression was inversely correlated with $\mathrm{Bcl}-2$ expression in head and neck adenoid cystic carcinoma tissue. It appeared likely that Bcl-2 inhibited beclin 1-dependent autophagy. This finding is consistent with those of previous studies on solid tumors, which have shown that $\mathrm{Bcl}-2$ negatively regulates beclin 1-dependent autophagic cell death $(9,23,32)$. Accordingly, it could be assumed that $\mathrm{Bcl}-2$ may be an oncogene that not only inhibits apoptosis but also blocks autophagy (33). In addition to Bcl-2, other anti-apoptotic proteins, bcl-xL, bcl-w, and $\mathrm{mcl}-1$ in the Bcl-2 family are also able to interact with beclin 1 and suppress autophagy (33). Camisasca et al. (34) reported that Bcl-2 expression emerged as an independent marker in survival analysis and the expression of $\mathrm{Bcl}-2$ family members seems to be an important marker of a favorable prognosis in oral squamous cell carcinoma. We found that $\mathrm{Bcl}-2$ expression showed a statistically significant correlation with perineural invasion but survival of negative $\mathrm{Bcl}-2$ expression in the positive Bcl-2 group was not significantly different. Therefore, further study on a larger scale will be necessary to explain the significance of $\mathrm{Bcl}-2$ expression in head and neck adenoid cystic carcinoma.

p53 is perspicuously involved in the development of head and neck adenoid cystic carcinoma. Mutations of the p53 gene are the most common genetic variations and are extensively distributed in head and neck adenoid cystic carcinoma cells (35). Because the effect of mutation prolongs the half-life of p53 through increased protein stability, tumors with missense mutations displayed positive nuclear immunoreactivity of p53. Wildtype p53 in head and neck adenoid cystic carcinoma is

\section{References}

1. Gondivkar SM, Gadbail AR, Chole R, Parikh RV. Adenoid cystic carcinoma: a rare clinical entity and literature review. Oral Oncol 2011; 47: 231-236, doi: 10.1016/j.oraloncology. 2011.01.009.

2. Dodd RL, Slevin NJ. Salivary gland adenoid cystic carcinoma: a review of chemotherapy and molecular therapies. Oral Oncol 2006; 42: 759-769, doi: 10.1016/j.oraloncology. 2006.01.001.

3. Lloyd S, Yu JB, Wilson LD, Decker RH. Determinants and patterns of survival in adenoid cystic carcinoma of the head and neck, including an analysis of adjuvant radiation generally negative for rapid degradation of normal p53 protein (20). Immunohistochemistry of p53 proteins in tumor cells may serve as an additional method for investigating the relationship between p53 and other protein expression levels to evaluate the status of this important tumor gene (20). Therefore, we analyzed the correlation between expression of beclin 1, Bcl-2, and p53 and found that p53 expression was positively correlated with beclin 1 expression, but not significantly correlated with $\mathrm{Bcl}-2$ expression. Variants of $p 53$ that preferentially localize to the cytoplasm effectively reperessed autophagy, whereas $p 53$ mutants that display a prominently nuclear distribution failed to inhibit autophagy in HCT 116 colon carcinoma cells (36). Therefore, further studies are necessary to determine the functions in autophagy of the mutant p53 protein localized in the nucleus of adenoid cystic carcinoma cells.

For overall survival, we found that the absent lymph node involvement group had better survival than the present group, a solid histological growth pattern was worse than a tubular and cribriform histological growth pattern, and well and moderate histological grade had better survival than poor histological grade. This result is consistent with previous findings that solid type is related to a poor prognosis, contrary to the cribriform or tubular types, which had a better prognosis $(1,37)$.

In conclusion, we have characterized the expression of beclin 1, Bcl-2, and p53 in head and neck adenoid cystic carcinoma tissue. Our results indicated that beclin 1 may be a novel, promising prognostic factor for clinical outcomes in head and neck adenoid cystic carcinoma patients. Therefore, it seems reasonable to assume that beclin 1 might play a part in the development of head and neck adenoid cystic carcinoma by interacting with Bcl-2 and p53. Further studies are warranted to confirm our findings and to clarify the involvement of beclin 1 in the development of head and neck adenoid cystic carcinoma.

\section{Acknowledgments}

Research supported by the Natural Science Foundation of Shandong Province (Grant \#2006GG2202034). therapy. Am J Clin Oncol 2011; 34: 76-81, doi: 10.1097/ COC.0b013e3181d26d45.

4. Ko YH, Lee MA, Hong YS, Lee KS, Jung CK, Kim YS, et al. Prognostic factors affecting the clinical outcome of adenoid cystic carcinoma of the head and neck. Jpn J Clin Oncol 2007; 37: 805-811, doi: 10.1093/jjco/hym119.

5. Chen N, Debnath J. Autophagy and tumorigenesis. FEBS Lett 2010; 584: 1427-1435, doi: 10.1016/j.febslet.2009.12.034.

6. Mizushima N, Klionsky DJ. Protein turnover via autophagy: implications for metabolism. Annu Rev Nutr 2007; 27: 1940, doi: 10.1146/annurev.nutr.27.061406.093749. 
7. Klionsky DJ, Emr SD. Autophagy as a regulated pathway of cellular degradation. Science 2000; 290: 1717-1721, doi: 10.1126/science.290.5497.1717.

8. Sinha S, Levine B. The autophagy effector Beclin 1: a novel BH3-only protein. Oncogene 2008; 27 (Suppl 1): S137S148, doi: 10.1038/onc.2009.51.

9. Won KY, Kim GY, Kim YW, Song JY, Lim SJ. Clinicopathologic correlation of beclin-1 and bcl-2 expression in human breast cancer. Hum Pathol 2010; 41: 107-112, doi: 10.1016/j.humpath.2009.07.006.

10. Huang X, Bai HM, Chen L, Li B, Lu YC. Reduced expression of LC3B-II and Beclin 1 in glioblastoma multiforme indicates a down-regulated autophagic capacity that relates to the progression of astrocytic tumors. J Clin Neurosci 2010; 17: 1515-1519, doi: 10.1016/j.jocn.2010.03.051.

11. Miracco C, Cosci E, Oliveri G, Luzi P, Pacenti L, Monciatti I, et al. Protein and mRNA expression of autophagy gene Beclin 1 in human brain tumours. Int $J$ Oncol 2007; 30: 429-436.

12. Shen Y, Li DD, Wang LL, Deng R, Zhu XF. Decreased expression of autophagy-related proteins in malignant epithelial ovarian cancer. Autophagy 2008; 4: 1067-1068.

13. Dong LW, Hou YJ, Tan YX, Tang L, Pan YF, Wang M, et al. Prognostic significance of Beclin 1 in intrahepatic cholangiocellular carcinoma. Autophagy 2011; 7: 1222-1229, doi: 10.4161/auto.7.10.16610.

14. Liang XH, Jackson S, Seaman M, Brown K, Kempkes B, Hibshoosh $\mathrm{H}$, et al. Induction of autophagy and inhibition of tumorigenesis by beclin 1 . Nature 1999; 402: 672-676, doi: $10.1038 / 45257$.

15. Furuya N, Yu J, Byfield M, Pattingre S, Levine B. The evolutionarily conserved domain of Beclin 1 is required for Vps34 binding, autophagy and tumor suppressor function. Autophagy 2005; 1: 46-52, doi: 10.4161/auto.1.1.1542.

16. Pattingre S, Tassa A, Qu X, Garuti R, Liang XH, Mizushima $\mathrm{N}$, et al. Bcl-2 antiapoptotic proteins inhibit Beclin 1dependent autophagy. Cell 2005; 122: 927-939, doi: 10.1016/j.cell.2005.07.002.

17. Levine B, Sinha S, Kroemer G. Bcl-2 family members: dual regulators of apoptosis and autophagy. Autophagy 2008; 4: 600-606.

18. Maiuri MC, Galluzzi L, Morselli E, Kepp O, Malik SA, Kroemer G. Autophagy regulation by p53. Curr Opin Cell Biol 2010; 22: 181-185, doi: 10.1016/j.ceb.2009.12.001.

19. Levine B, Abrams J. p53: The Janus of autophagy? Nat Cell Biol 2008; 10: 637-639, doi: 10.1038/ncb0608-637.

20. Kazakov DV, Grossmann P, Spagnolo DV, Vanecek T, Vazmitel M, Kacerovska D, et al. Expression of p53 and TP53 mutational analysis in malignant neoplasms arising in preexisting spiradenoma, cylindroma, and spiradenocylindroma, sporadic or associated with Brooke-Spiegler syndrome. Am J Dermatopathol 2010; 32: 215-221, doi: 10.1097/DAD.0b013e3181e1d1e8.

21. Szanto PA, Luna MA, Tortoledo ME, White RA. Histologic grading of adenoid cystic carcinoma of the salivary glands. Cancer 1984; 54: 1062-1069, doi: 10.1002/1097-0142 (19840915)54:6<1062::AID-CNCR2820540622>3.0.CO;2-E.

22. Li BX, Li CY, Peng RQ, Wu XJ, Wang HY, Wan DS, et al. The expression of beclin 1 is associated with favorable prognosis in stage IIIB colon cancers. Autophagy 2009; 5: 303-306, doi: 10.4161/auto.5.3.7491.
23. Huang JJ, Zhu YJ, Lin TY, Jiang WQ, Huang HQ, Li ZM. Beclin 1 expression predicts favorable clinical outcome in patients with diffuse large B-cell lymphoma treated with R-CHOP. Hum Pathol 2011; 42: 1459-1466, doi: 10.1016/ j.humpath.2010.12.014.

24. Ahn CH, Jeong EG, Lee JW, Kim MS, Kim SH, Kim SS, et al. Expression of beclin-1, an autophagy-related protein, in gastric and colorectal cancers. APMIS 2007; 115: 13441349, doi: 10.1111/j.1600-0463.2007.00858.x.

25. Li Z, Chen B, Wu Y, Jin F, Xia Y, Liu X. Genetic and epigenetic silencing of the beclin 1 gene in sporadic breast tumors. BMC Cancer 2010; 10: 98, doi: 10.1186/1471-240710-98.

26. Chen C, Ma Q, Ma X, Liu Z, Liu X. Association of elevated HIF-2alpha levels with low Beclin 1 expression and poor prognosis in patients with chondrosarcoma. Ann Surg Oncol 2011; 18: 2364-2372, doi: 10.1245/s10434-011-1587-5.

27. Miracco C, Cevenini G, Franchi A, Luzi P, Cosci E, Mourmouras V, et al. Beclin 1 and LC3 autophagic gene expression in cutaneous melanocytic lesions. Hum Pathol 2010; 41: 503-512, doi: 10.1016/j.humpath.2009.09.004.

28. Levine B, Kroemer G. Autophagy in the pathogenesis of disease. Cell 2008; 132: 27-42, doi: 10.1016/j.cell.2007. 12.018.

29. Mathew R, Kongara S, Beaudoin B, Karp CM, Bray K, Degenhardt K, et al. Autophagy suppresses tumor progression by limiting chromosomal instability. Genes Dev 2007; 21: 1367-1381, doi: 10.1101/gad.1545107.

30. Karantza-Wadsworth V, Patel S, Kravchuk O, Chen G, Mathew R, Jin S, et al. Autophagy mitigates metabolic stress and genome damage in mammary tumorigenesis. Genes Dev 2007; 21: 1621-1635, doi: 10.1101/gad.1565707.

31. Young AR, Narita M, Ferreira M, Kirschner K, Sadaie M, Darot $\mathrm{JF}$, et al. Autophagy mediates the mitotic senescence transition. Genes Dev 2009; 23: 798-803, doi: 10.1101/gad. 519709.

32. Martin SJ. Oncogene-induced autophagy and the Goldilocks principle. Autophagy 2011; 7: 922-923, doi: 10.4161/auto.7.8.15821.

33. Maiuri MC, Criollo A, Kroemer G. Crosstalk between apoptosis and autophagy within the Beclin 1 interactome. EMBO J 2010; 29: 515-516, doi: 10.1038/emboj.2009.377.

34. Camisasca DR, Honorato J, Bernardo V, da Silva LE, da Fonseca EC, de Faria PA, et al. Expression of Bcl-2 family proteins and associated clinicopathologic factors predict survival outcome in patients with oral squamous cell carcinoma. Oral Oncol 2009; 45: 225-233, doi: 10.1016/ j.oraloncology.2008.05.021.

35. Costa AF, Altemani A, Vekony H, Bloemena E, Fresno F, Suarez C, et al. Genetic profile of adenoid cystic carcinomas (ACC) with high-grade transformation versus solid type. Cell Oncol 2011; 34: 369-379, doi: 10.1007/s13402-011-0037-5.

36. Morselli E, Tasdemir E, Maiuri MC, Galluzzi L, Kepp O, Criollo A, et al. Mutant p53 protein localized in the cytoplasm inhibits autophagy. Cell Cycle 2008; 7: 3056-3061, doi: 10.4161/cc.7.19.6751.

37. Locati LD, Perrone F, Losa M, Mela M, Casieri P, Orsenigo $\mathrm{M}$, et al. Treatment relevant target immunophenotyping of 139 salivary gland carcinomas (SGCs). Oral Oncol 2009; 45: 986-990, doi: 10.1016/j.oraloncology.2009.05.635. 